\title{
Soybean Seeds: A Practical Host for the Production of Functional Subunit Vaccines
}

\author{
Laura C. Hudson, ${ }^{1}$ Renu Garg, ${ }^{1,2}$ Kenneth L. Bost, ${ }^{1,3}$ and Kenneth J. Piller ${ }^{1,3}$ \\ ${ }^{1}$ Soymeds, Inc., Davidson, NC 28036, USA \\ ${ }^{2}$ CSIR-Institute of Microbial Technology, Sector 39A, Chandigarh 160036, India \\ ${ }^{3}$ Department of Biology, University of North Carolina at Charlotte, 9201 University City Boulevard, Charlotte, NC 28223, USA \\ Correspondence should be addressed to Kenneth J. Piller; kjpiller@uncc.edu
}

Received 21 January 2014; Accepted 17 March 2014; Published 14 April 2014

Academic Editor: Chenming (Mike) Zhang

Copyright (C) 2014 Laura C. Hudson et al. This is an open access article distributed under the Creative Commons Attribution License, which permits unrestricted use, distribution, and reproduction in any medium, provided the original work is properly cited.

\begin{abstract}
Soybean seeds possess several inherent qualities that make them an ideal host for the production of biopharmaceuticals when compared with other plant-based and non-plant-based recombinant expression systems (e.g., low cost of production, high protein to biomass ratio, long-term stability of seed proteins under ambient conditions, etc.). To demonstrate the practicality and feasibility of this platform for the production of subunit vaccines, we chose to express and characterize a nontoxic form of $S$. aureus enterotoxin $\mathrm{B}(\mathrm{mSEB})$ as a model vaccine candidate. We show that soy-mSEB was produced at a high vaccine to biomass ratio and represented $\sim 76$ theoretical doses of human vaccine per single soybean seed. We localized the model vaccine candidate both intracellularly and extracellularly and found no difference in $\mathrm{mSEB}$ protein stability or accumulation relative to subcellular environment. We also show that the model vaccine was biochemically and immunologically similar to native and recombinant forms of the protein produced in a bacterial expression system. Immunization of mice with seed extracts containing mSEB mounted a significant immune response within 14 days of the first injection. Taken together, our results highlight the practicality of soybean seeds as a potential platform for the production of functional subunit vaccines.
\end{abstract}

\section{Introduction}

The use of transgenic plants to express recombinant proteins has gained popularity over the past decade and represents a growing segment in the pharmaceutical industry. Currently, the bulk of biopharmaceuticals are produced in recombinant microbe expression systems or insect and mammalian cell cultures. However, as with all protein expression systems, there are advantages and disadvantages to these systems which are described in several review articles [1-3]. Some of these limitations include the types of proteins that can be produced and in the posttranslational processing that can be achieved making production costs prohibitively high. Based on these limitations, an increased demand for biopharmaceuticals will require improved and cost effective manufacturing practices and practical transportation methods for a global community.

As an alternative to traditional systems, a number of pharmaceuticals have been successfully produced in various plant-based expression systems. Although these plant systems offer great potential, they too present several challenges. Many crop systems used to date have a low protein content which can increase the overall production costs since purification expenses are typically inversely proportional to final target protein concentration in plant biomass. Therefore, crops with higher protein content and a compact biomass are more cost effective for molecular farming. When it comes to express large amounts of a pharmaceutical protein in a plant host, soybean should be considered as a practical alternative. The soybean system has many distinct advantages when compared with existing expression systems. For example, soybeans contain $\sim 40 \%$ protein by dry mass and therefore represent one of the richest natural sources of protein known. Given this high protein content, it is possible to express large amounts of transgenic protein in a single soybean seed. Furthermore, with typical transgenic expression levels of $1-4 \%$ of total soluble protein (TSP), there are few, if any, host systems that can produce such levels of foreign 
protein based on weight. Second, soybean is a relatively easy and inexpensive plant to grow making the production of biopharmaceuticals in soybeans extremely cost effective. Another advantage of soybean is the proven stability of proteins in dry mass over extended periods of time, suggesting that pharmaceuticals could be shipped as crushed seed or processed powder and stored under ambient conditions, thus eliminating any requirement for a cold chain. Soybean also possesses the necessary machinery for eukaryotic posttranslational modification [4] and is capable of generating large and complex recombinant proteins $(>600 \mathrm{kDa})$ that are often recalcitrant to expression in traditional expression systems [5]. Given these advantages, soybean represents a practical host for the production of proteins for numerous applications.

Soybean-based vaccines, in particular, offer specific advantages over vaccines produced in other, more conventional systems. For example, soy-based vaccines could either be formulated into consumables for oral delivery or purified for injection or other downstream uses. In an effort to demonstrate the practicality of soybean seeds as a host system for manufacturing protein-based vaccine candidates we chose to express a nontoxic form of Staphylococcal enterotoxin B (SEB) as a model vaccine candidate. SEB is a well-characterized, superantigen-like exotoxin produced by the bacteria Staphylococcus aureus. SEB mediates its toxicity by linking MHC class II molecules with $\mathrm{T}$ cell receptors outside of the antigen binding site [6]. Clinical symptoms of SEB poisoning include anorexia, nausea, vomiting, and diarrhea. Three-dimensional structures of SEB and its complex with MHC class II molecules have been elucidated [7, 8] and several biochemical studies have offered clues to the biologically important regions of this protein [9-12]. While SEB remains a CDC Category B toxin, there is still no vaccine for SEB poisoning in the market.

Due to the inherent superantigen properties of SEB, the native toxin cannot be used as a practical vaccine antigen. However, mutated forms of the protein that remove superantigenicity while leaving immunogenic capacity intact should serve as a viable vaccine option. Such alterations can be accomplished using chemical treatment or genetic manipulation to introduce site specific mutations $[13,14]$. Various mutagenesis studies have identified important mutations that reduce or eliminate biological activity of the wild-type toxin while retaining immunogenic epitopes that elicit protective antibody responses $[10,12,15]$. Specifically, single mutations of key residues in the hydrophobic binding loop (L45R), polar binding pocket (Y89A), and disulfide loop (Y94A) in recombinant forms of SEB eliminated binding to the $\mathrm{MHC}$ class II receptor [15] but did not disrupt native structure and generated effective immune responses. This triple mutant form of SEB ( $\mathrm{mSEB}$ ) possessed greatly diminished biological activity and was reported to be tolerated as a vaccine in both mice and nonhuman primates. The triple mutant also offered protection to immunized animals when challenged with native SEB (nSEB) [14-16]. Synthetic mSEB has also been used as a model antigen and overexpressed in tobacco (NT1) cells using a geminivirus-based replicon system [17].
In this study we engineered a model vaccine candidate to demonstrate the practicality of soybean as a platform for the production of vaccine candidates and other therapeutics. Two well-characterized plant promoters were used to target expression to seeds, and different signal peptides were included to evaluate accumulation in different subcellular locations. We found that all recombinant forms of the model $\mathrm{mSEB}$ vaccine were expressed at a high vaccine to biomass ratio and were accurately processed by the plant machinery. We show that a soy-mSEB vaccine candidate was biochemically equivalent to, and exhibited immunological properties that were analogous to, those exhibited by $E$. coli-derived $\mathrm{mSEB}$ and native SEB. Functionality of soymSEB was shown in groups of mice immunized with the model vaccine candidate. Taken together, these findings demonstrate the practicality of soybean as a cost-effective host for the production of important vaccine candidates.

\section{Materials and Methods}

2.1. Seed-Specific SEB Expression Cassette Design and Construction. Soybean codon optimized mutant SEB genes containing sequences encoding the native SEB N-terminal signal peptide sequence and the native soybean glycinin $\mathrm{N}$-terminal signal peptide sequence were synthesized from GeneArt (Life Technologies Carlsbad, CA) and DNA 2.0 (Menlo Park, CA), respectively.

Restriction endonuclease NcoI and XbaI sites were engineered on the $5^{\prime}$ and $3^{\prime}$ termini to facilitate subcloning. Following digestion with $\mathrm{NcoI}$ and $\mathrm{XbaI}$ the synthetic genes were isolated from an agarose gel and ligated into linearized pPTN200 [19]. The resulting pPTNST108 construct contained the $7 \mathrm{~S} \beta$-conglycinin promoter, Tobacco Etch Virus (TEV) translational enhancer, native SEB signal peptide, mutant (L45R, Y89A, Y94A) SEB open reading frame (ORF), and 35S terminator. The construct pPTN764 contained the soybean $11 S$ glycinin promoter and signal peptide sequence, an identical mutant SEB ORF, and 35S terminator elements. Both constructs included a cassette encoding for phosphinothricin acetyltransferase (bar gene) under the control of the nopaline synthase (nos) promoter and terminator elements. Following subcloning, the identity of both constructs was confirmed using multiple restriction digestion analyses. Integrity of the mSEB ORF was verified by double-stranded sequencing (Davis Sequencing, LLC, Davis CA). Soybean transformations were carried out as previously described [20-22].

\subsection{Preparation of Genomic DNA and PCR. Genomic DNA} was prepared from cotyledon tissue using the Maxwell 16 Instrument and the Maxwell Tissue DNA Purification Kit (Promega, Madison, WI). Duplex PCR reactions were carried out using GoTaq Flexi DNA polymerase (Promega, Madison, WI) with the following primers: SEB forward (5'-GGACAAGCGCCTCTTCATCTC-3'), SEB reverse (5'-AGGTACACCTCGATCTTCACG-3'), VSP (vegetative storage protein) forward $\left(5^{\prime}\right.$-GCTTCCACACATGGGAGCAG- $\left.3^{\prime}\right)$, and VSP reverse $\left(5^{\prime}\right.$-CCTCTGTGGTCTCCAAGCAG- $\left.3^{\prime}\right)$. 
Following an initial denaturation step at $95^{\circ} \mathrm{C}$ for 5 minutes the reactions were subjected to 35 cycles comprising denaturation at $95^{\circ} \mathrm{C}$ for $30 \mathrm{sec}$, annealing at $52^{\circ} \mathrm{C}$ for $45 \mathrm{sec}$, and extension at $72^{\circ} \mathrm{C}$ for $1 \mathrm{~min}$. PCR products were visualized on $1.5 \%$ agarose gels stained with ethidium bromide.

\subsection{Seed Protein Extracts and Western Blot Analysis. Soluble} seed protein was extracted from either seed chips or ground seed powder using an extraction buffer of phosphate-buffered saline (PBS) and sonication for 20 seconds. Samples were clarified from soluble debris by centrifugation and protein concentrations were determined with the Bradford Reagent (Bio-Rad Laboratories, Hercules, CA) using bovine serum albumin (BSA) as a standard.

Soluble protein extracts $(3 \mu \mathrm{g})$ were subjected to $10 \%$ SDS-PAGE under nonreducing conditions. Unless noted, SDS sample buffer did not contain $\beta$-mercaptoethanol. Samples were transferred in 1x CAPS buffer (N-cyclohexyl-3aminopropanesulfonic acid, $\mathrm{pH} 11$ ) containing $10 \%$ methanol to Immobilon-P membrane (Millipore, Bedford, MA, USA). Membranes were blocked overnight with $5 \%$ nonfat milk in 1XPBS at $4^{\circ} \mathrm{C}$, followed by Western analysis with an in-house primary antibody $(1: 5000)$ and goat anti-rabbit IgG HRP secondary antibody $(1: 5000)$. Immunodetection was carried out using the SuperSignal West Pico substrate kit (Thermo Scientific, Rockford, IL, USA). For protein visualization, membranes were stained with Coomassie blue for 1 minute followed by destaining.

\subsection{Quantification of Recombinant Protein in Seed Extracts.} Quantification of recombinant soy-mSEB protein expression within seed extracts were determined by Western blot analysis. Protein extracts from a master mix of seed powder consisting of 100 seeds from the T3 generation of ST108 were compared to known amounts of purified recombinant (E. coli) mutant SEB standards by Western blot as described above. X-ray films of the results were scanned for densitometric analysis. Integrated density was determined using Image J software. A standard curve was plotted using the integrated densities of known mSEB standards. A best-fit standard curve was used to determine the amount of SEB in seed extracts. Theoretical vaccine yields were estimated based on the amount of soluble protein from a starting biomass of $1 \mathrm{~L}$ of soy powder (approximately 800 grams) as previously described [23]. Assumptions included $160 \mathrm{mg}$ dry weight of an average soybean seed, $40 \%$ seed protein composition, $1.2 \%$ expression level for $\mathrm{mSEB}$, and $10 \mu \mathrm{g}$ for a single human vaccine dose, which is similar to the dose recommended for recombinant hepatitis B surface antigen immunizations [24].

\subsection{Protein Characterization and $N$ Terminal Sequencing} of SEB Fragments. Soybean mSEB was immunoprecipitated using anti-SEB antibodies and protein-A agarose beads (Sigma-Aldrich, St. Louis, MO). The immunoprecipitated protein was electrophoresed on a 10\% SDS-PAGE preparative gel in the absence of $\beta$-mercaptoethanol and soy-mSEB protein was eluted from the gel after Coomassie staining. Eluted protein was dialyzed against PBS and concentrated by using centriplus YM-3 centrifugal filter devices (Millipore, Bedford, MA). Concentrated protein was then mixed with SDS-PAGE sample buffer containing $\beta \mathrm{ME}$, electrophoresed on a $12 \%$ SDS-PAGE gel and immobilized onto Immobilon-PVDF membrane. The membranes were stained with Coomassie blue for $1 \mathrm{~min}$, followed by destaining and extensive washes with water. Bands of interest were excised for protein sequencing (Iowa State University protein sequencing facility) of N-terminal amino acids. For signal peptide cleavage prediction, full length amino acid sequences were entered into SignalP 4.1 software [18].

2.6. Confocal Microscopy. Whole seed tissue was imbibed for 12 hours in 1XPBS and fixed as described previously [5, 22, 25]. Briefly, sections were permeabilized with 1 XPBS containing $0.2 \%$ Tween-20 for 10 minutes, followed by blocking in 1XPBS supplemented by $3 \%$ BSA overnight at $4^{\circ} \mathrm{C}$. Tissue was incubated with rabbit anti-SEB serum $(1: 200)$ for $4 \mathrm{~h}$ at $23^{\circ} \mathrm{C}$, followed by incubation with an Alexa Fluor 594 goat antirabbit antibody $(1: 200)$ for $1 \mathrm{~h}$ at $23^{\circ} \mathrm{C}$. Lastly, tissue sections were incubated with $4^{\prime}$,6-diamidino-2-phenylindole (DAPI) for 5 minutes at 1:500 and cover slips were mounted using Gel/Mount aqueous mounting media. Images were collected with a LSM 710 Spectral Confocor 3 Confocal Microscope (Carl Zeiss, Inc.) under 20x magnification and a $405 \mathrm{~nm}$ laser to visualize nuclei stained with DAPI in conjunction with a $561 \mathrm{~nm}$ laser to collect emitted fluorescence from the Alexa Fluor 594 antibody. Stacks of images (26 optical sections, $20 \mathrm{~nm}$ apart) were collected in the $Z$ plane of the specimens and projected to form a single image using the ZEN Light Edition software.

2.7. ELISAs. Three different antibodies were used for ELISAs: one used a rabbit polyclonal anti-SEB antibody (generated in house against $E$. coli-derived $\mathrm{mSEB}$ ) at a concentration of 1:500; a second used a commercial HRP-conjugated sheep anti-SEB polyclonal antibody (Abcam number ab15925) at a concentration of 1:1000; and a third used a mouse monoclonal anti-SEB (Abcam number ab6064) at a concentration of $1: 1000$. Microtiter plates were coated with $100 \mathrm{ng} /$ well of each protein (soy-mSEB, rSEB, nSEB, or cholera toxin as a control) in $100 \mu \mathrm{L}$ of $0.1 \mathrm{M}$ bicarbonate buffer ( $\mathrm{Ph} 8.0)$ at $4^{\circ} \mathrm{C}$ overnight. Plates were washed in 1 XPBS, $0.1 \%$ Tween20 , and blocked with $2 \%$ BSA for 1 hour. After a second wash detection antibodies were added for 2 hours at room temperature. The in-house anti-SEB ELISA was washed and an anti-rabbit IgG-HRP conjugate was added for 2 hours at room temperature followed by another wash and the addition of the TMB substrate. The commercial HRP conjugated polyclonal anti-SEB ELISA was washed and incubated with TMB substrate (BioFX). The commercial monoclonal antiSEB ELISA was washed and incubated with HRP-conjugated anti-mouse IgG for 2 hours at room temperature followed by a final wash and the addition of TMB. All reactions were stopped using $0.5 \mathrm{M}$ sulfuric acid and absorbance was read at $405 \mathrm{~nm}$. Absorbance values have not been background subtracted for any of the values given and data are represented as mean \pm standard deviation. 


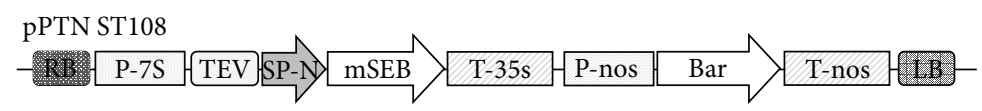

(a)

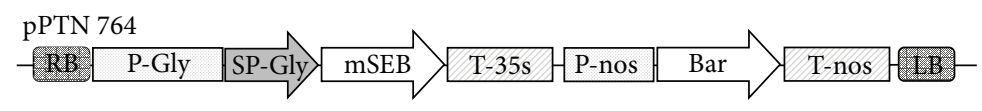

(b)

FIGURE 1: Gene construct design. (a) The pPTN ST108 binary vector used for Agrobacterium-mediated transformation comprising the following regulatory elements: $7 \mathrm{~S}$ soybean $\beta$-conglycinin promoter (P-7S), tobacco etch virus translational enhancer element (TEV), native SEB bacterial signal peptide (SP-N), mutant SEB gene (mSEB), and 35S cauliflower mosaic virus terminator element (T-35s) followed by the selectable marker cassette (nopaline synthase promoter (P-nos), phosphinothricin acetyltransferase gene (bar), and nopaline synthase terminator element (T-nos)). (b) The pPTN 764 binary vector contained soybean 11S glycinin promoter (P-Gly), soybean glycinin signal peptide (SP-Gly), mSEB, and T-35S, followed by the selectable marker cassette. Arrows show orientation of cassettes relative to the right border (RB) and left border (LB) sequences.

2.8. Immunization of Mice and Detection of Antibody Titers. Seed extract containing approximately $10 \mu \mathrm{g}$ of the target soy$\mathrm{mSEB}$ was emulsified in an equal volume of either Complete Freund's adjuvant (primary immunization) or incomplete Freund's adjuvant (booster immunizations). Preimmune serum was collected prior to the first injection and 1 day prior to each booster immunization from groups $(n=4)$ of 4-week-old female BALB/c mice (The Jackson Laboratory, Bar Harbor, ME). Intraperitoneal immunization with seed extract plus adjuvant $(10 \mu \mathrm{g}$ CT) took place on day 0 with boosts on days 14 and 28. To determine anti-SEB titers in sera of immunized mice, microtiter plates were coated with $20 \mathrm{ng} /$ well of native SEB (Toxin Technology, Sarasota Florida) in $100 \mu \mathrm{L}$ of carbonate buffer at $4^{\circ} \mathrm{C}$ overnight. Wells were blocked with 3\% BSA in PBS. After washing, sera were tested using serial 3 -fold dilutions beginning at 1:1000 and were incubated for 3 hours at $23^{\circ} \mathrm{C}$ followed by washes. An HRP-conjugated goat anti-mouse IgG (Southern Biotech, Birmingham, AL) was added for two hours at $23^{\circ} \mathrm{C}$. Following washes, plates were incubated with TMB substrate (BioFX) and enzymatic reactions were stopped with the addition of $0.5 \mathrm{M}$ sulfuric acid and absorbance was read at $405 \mathrm{~nm}$. Absorbance values represent serum diluted at $1: 27,000$ and have not been background subtracted and data are represented as mean \pm standard deviation.

\section{Results}

3.1. Molecular Characterization of Transgenic Events. A synthetic mSEB gene was codon optimized for expression in Glycine max and used to create the binary vectors pPTNST108 and pPTN764 (Figure 1). The pPTNST108 construct contains the native $S$. aureus SEB signal peptide sequence and an open reading frame encoding a triple mutant SEB cloned downstream of the soybean $\beta$-conglycinin promoter. The pPTN764 construct contains an identical mutant SEB open reading frame cloned downstream of the native soybean glycinin promoter and signal peptide elements.

Agrobacterium-mediated transformation was used to transform soybean somatic embryos. A total of 25 separate transgenic events were obtained using pPTNST108 and 12 transgenic events were obtained using pPTN764. These events were taken to maturity and all appeared to be phenotypically similar to wild-type nontransgenic control plants. A large-scale molecular screen involving duplex PCR and Western analysis was used to identify specific progeny and lines to be moved forward. A representation of the data generated by the molecular screen is shown in Figure 2.

T1 seeds derived from each transformation event were collected and cotyledon chips were prepared from 8 individual seeds. For duplex PCR, genomic DNA was incubated with primers designed to amplify a diagnostic 796 bp soymSEB fragment. Primers were also included to duly amplify a 325 bp vegetative storage protein fragment which served as an internal control. For the characterization of ST108 and 764 transformation events shown in Figure 2, duplex PCR identified the mSEB transgene in 7 of the $8 \mathrm{~T} 1$ progenies examined (Figures 2(a) and 2(b)). To identify those progenies with detectable $\mathrm{mSEB}$, seed proteins were extracted from each chip, separated under nonreducing SDS-PAGE conditions, and detected by Western analysis. For the representative samples shown in Figure 2, all 7 of the PCR-positive progenies also accumulated immunoreactive protein that was detected by rabbit sera containing anti-SEB polyclonal antibodies (Figures $2(\mathrm{c})$ and $2(\mathrm{~d})$ ). The immunoreactive protein migrated with a $\mathrm{MW}$ of $\sim 28 \mathrm{kDa}$, consistent with the predicted $\mathrm{MW}$ of $28.3 \mathrm{kDa}$ for $\mathrm{mSEB}$. The lack of detectable protein in nontransgenic and wild-type seed extracts (negative control) demonstrated the specificity of the antibody for the mSEB epitopes. Recombinant $\mathrm{mSEB}$ protein purified from $E$. coli was included on each gel and served as an internal positive control.

Western analyses resulting from a large scale screen of all events revealed that progeny from 18 of the 25 ST108 transgenic events (72\%) and 6 of the 12764 transgenic events (50\%) expressed $\mathrm{mSEB}$ protein. Based on $\mathrm{mSEB}$ expression levels in these experiments, lead progenies were taken to maturity and characterized over multiple generations. The examples shown in Figure 2 represent some of the highest expressing lines that were propagated over several generations and used for subsequent studies. The stability of soymSEB was demonstrated by Western analysis in T2 and 


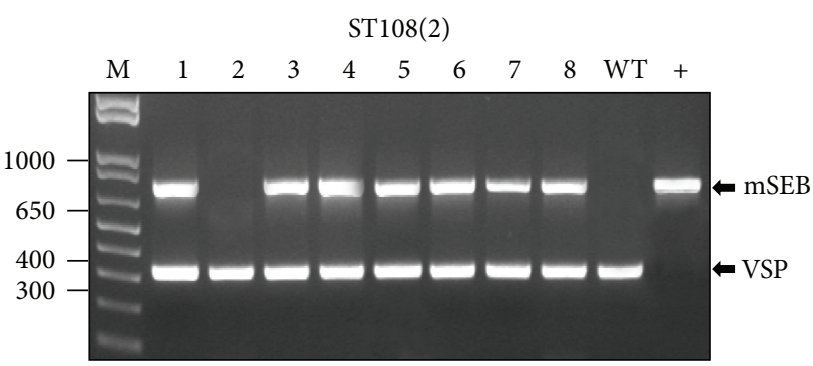

(a)

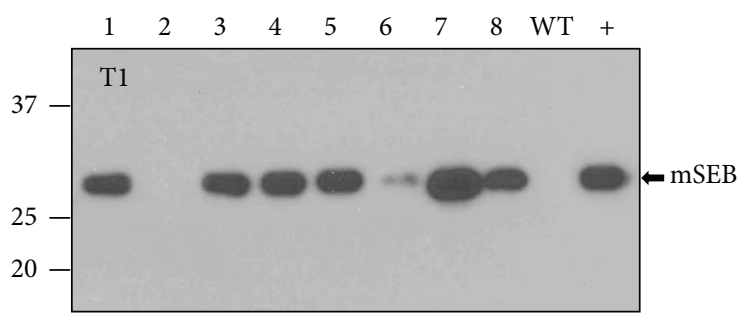

(c)

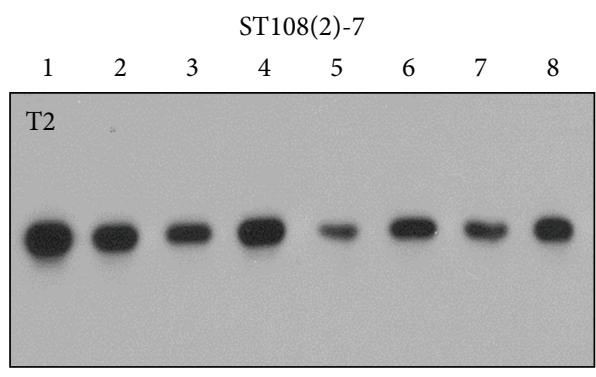

(e)

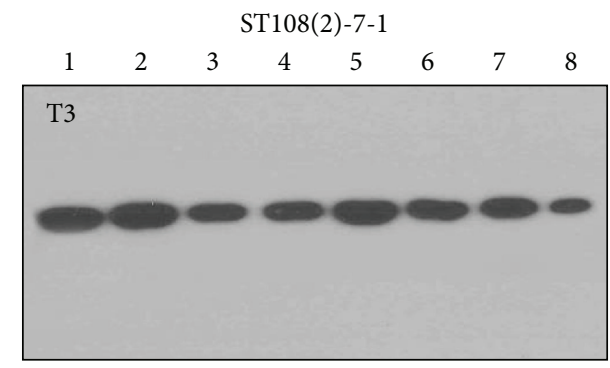

(g)

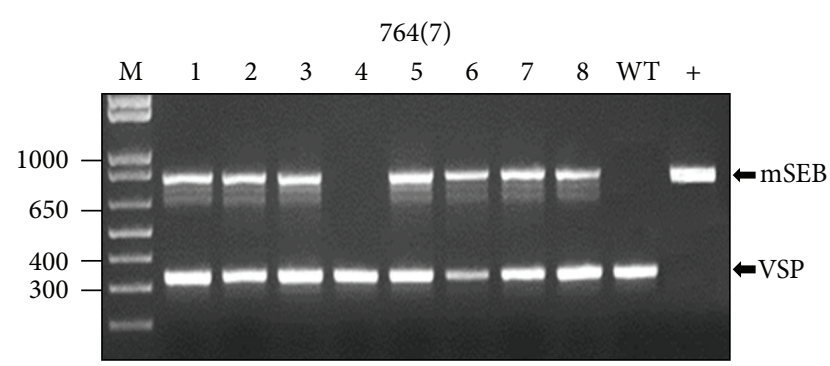

(b)

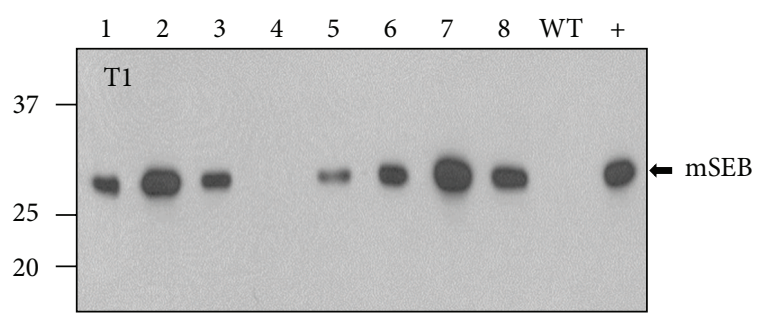

(d)

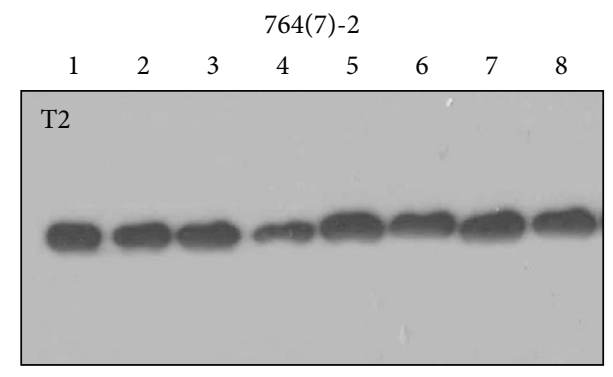

(f)

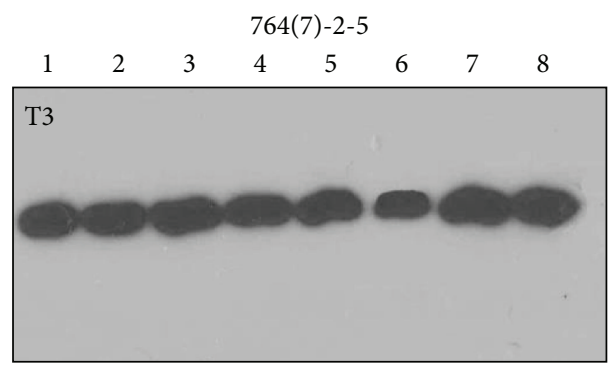

(h)

FIGURE 2: Molecular characterization of soy-mSEB events. (a) and (b) Duplex PCR of 8 T1 progeny from the indicated transformation events. WT: nontransgenic (negative control); +: plasmid DNA (positive control). Arrow shows position of amplified DNA fragments derived from $\mathrm{mSEB}$ and vegetative storage protein (VSP). Sizes of molecular weight markers are shown in base pairs. (c) and (d) Western blot of protein derived from the T1 progeny shown in (a) and (b). Arrow indicates soy-mSEB immunoreactive protein. Sizes of molecular weight standards are shown as $\mathrm{kDa}$. (e) and (f) Western blots of $\mathrm{T} 2$ progeny from the indicated events. $(\mathrm{g})$ and (h) Western blots of $\mathrm{T} 3$ progeny from the indicated events.

T3 generations (Figures 2(e), 2(f), 2(g), and 2(h)) and all subsequent generations (data not shown). Southern results preformed on $\mathrm{T} 1$ progeny suggested the presence of up to 3 copies of the transgene present at multiple loci.

All plants propagated and taken to maturity were subjected to foliar spray with Ignite 280 SL herbicide to monitor for the expression of the herbicide selectable marker. There was a direct correlation between plants lacking the transgene and severe leaf chlorosis. All plants that contained the transgene and accumulated mSEB showed no visible signs of chlorosis (data not shown).

The approximate level of soy-mSEB protein expression was determined by semiquantitative Western analysis. Known amounts of seed protein (extracted from a master powder mix of 100 ST108 homozygous T3 seeds) and purified recombinant $\mathrm{mSEB}$ (quantification standards) were used in these experiments (Figure 3(a)). X-ray films of the Western blots were subjected to densitometric examination, and 


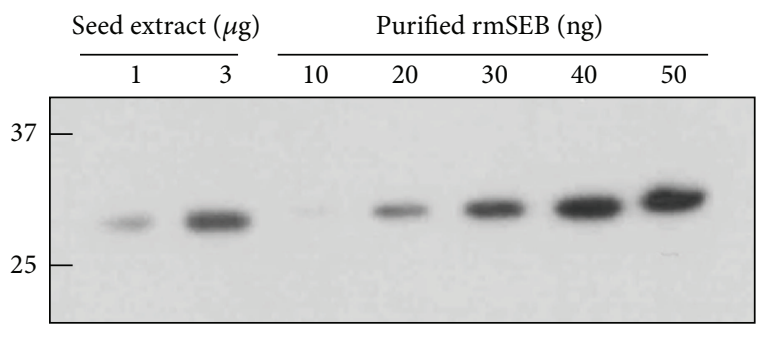

(a)

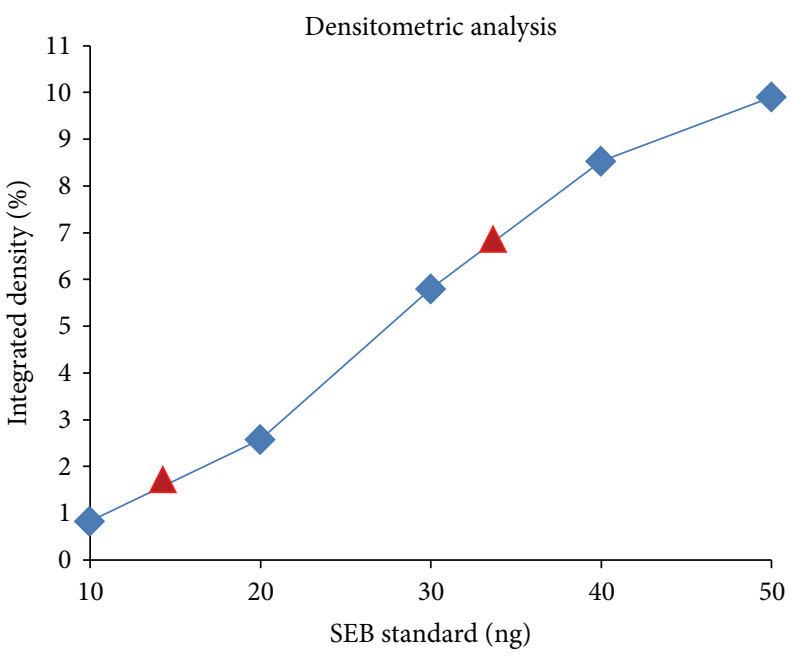

(b)

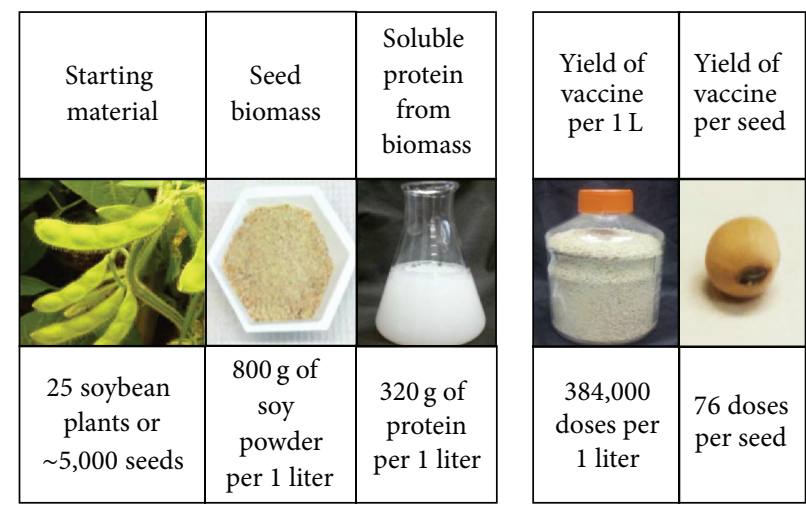

(c)

Figure 3: Quantification of soy-mSEB. (a) Known amounts of total seed protein (ST108, T3 generation) and various known amounts of purified E. coli-derived mSEB protein (standards) were separated under nonreducing SDS-PAGE and subjected to Western analysis. (b) A standard curve generated from the five known standards following densitometric analysis of the film shown in (a). (c) Chart showing theoretical number of vaccine doses present within a single transgenic soybean seed and in a 1 liter volume of crushed soybean powder. Calculations assume 200 soybeans per plant, $160 \mathrm{mg}$ average seed weight, $40 \%$ seed protein content, $1.2 \% \mathrm{mSEB}$ expression, and a $10 \mu \mathrm{g}$ human vaccine dose, which is similar to the dose recommended for recombinant hepatitis B surface antigen immunizations [18]. The calculations above do not account for any losses during the purification procedures.

a standard curve was generated. Extrapolation from this curve indicated $13.7 \mathrm{ng} \mathrm{mSEB}$ present in $1000 \mathrm{ng}$ total seed protein (1.37\% TSP) and $33.6 \mathrm{ng} \mathrm{mSEB}$ present in $3000 \mathrm{ng}$ protein $(1.12 \%$ TSP). Using an average of these numbers, we determined that soy-mSEB represents $\sim 1.2 \%$ of total soluble seed protein (Figure $3(\mathrm{~b})$ ). These results were also verified by ELISA and imply that an average ST108 soybean seed (160 mg dry weight) with a protein composition of $40 \%$ and transgene expression level of $1.2 \%$ contains 768 theoretical micrograms of mSEB or $76.810 \mu \mathrm{g}$ human doses of vaccine. This equates to 384,000 vaccine doses produced in seeds produced by $\sim 25$ soybean plants (Figure 3(c)).

3.2. Soy-mSEB Protein Characterization, N Terminal Sequencing, and Signal Peptide Cleavage. Native SEB is a single polypeptide with a known disulfide loop that is essential for mitogenic activity. The cysteines responsible for the disulfide bridge are located at amino acid positions 93 and 113 . We noticed that full length soy-mSEB protein could only be detected using nonreducing SDS-PAGE conditions (Figure 2) but not using standard reducing conditions (data not shown). This observation suggested nicking or proteolytic cleavage somewhere within mSEB. To examine this possibility further, soy protein from ST108 and 764 transformation events was compared with E. coli-derived $\mathrm{mSEB}$ and native SEB protein under reducing and nonreducing conditions. While the inclusion of $\beta$-mercaptoethanol as a reducing agent did not significantly alter the mobility of the E. coli-derived $\mathrm{mSEB}$ or native SEB proteins in SDS-PAGE, the inclusion of $\beta$ mercaptoethanol resulted in the detection of two smaller fragments with mobilities of $\sim 12$ and $16 \mathrm{kDa}$ in both soy samples (Figures 4(a) and 4(b)). The appearance and sizes of these fragments are consistent with cleavage within the 


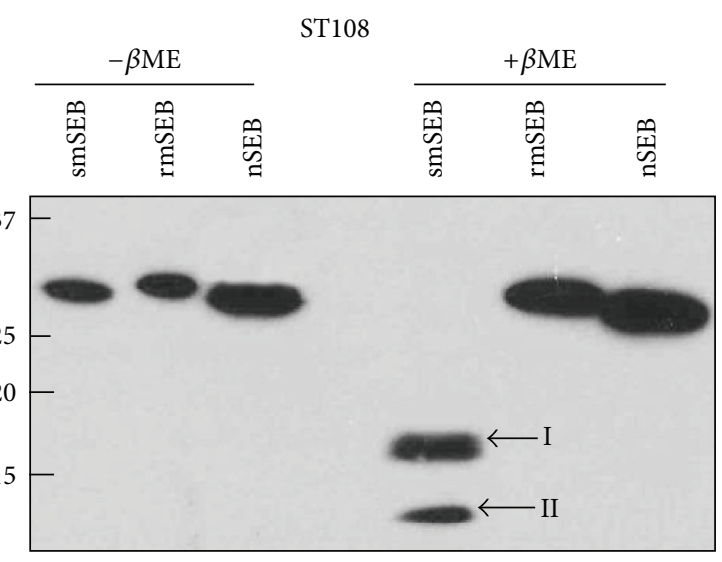

(a)

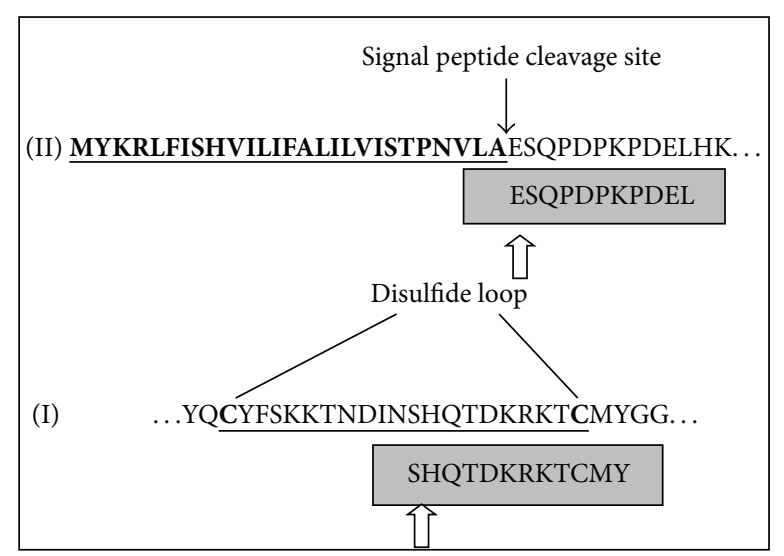

(c)

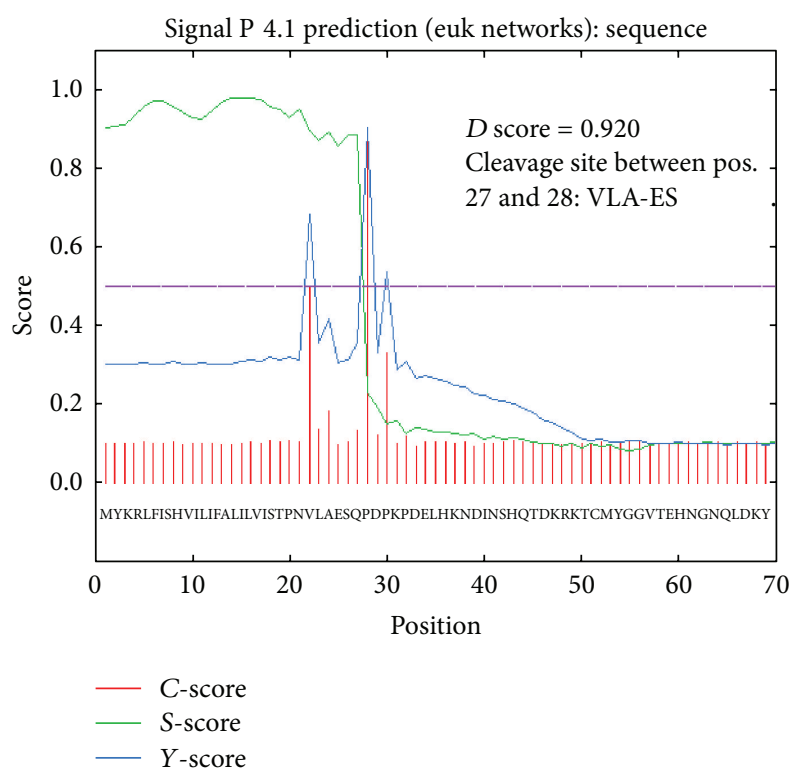

(e)
764

$\frac{c}{+\beta \mathrm{ME}}$

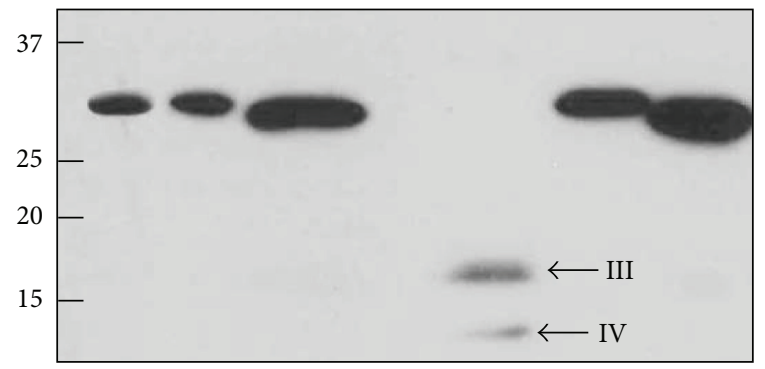

(b)

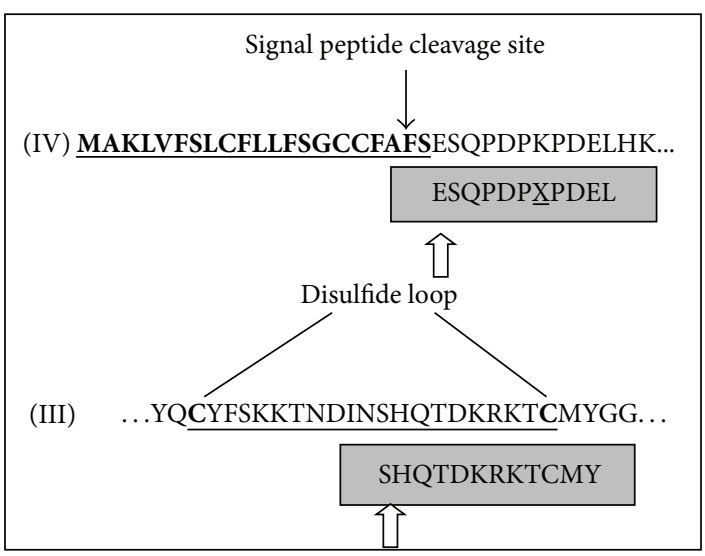

(d)

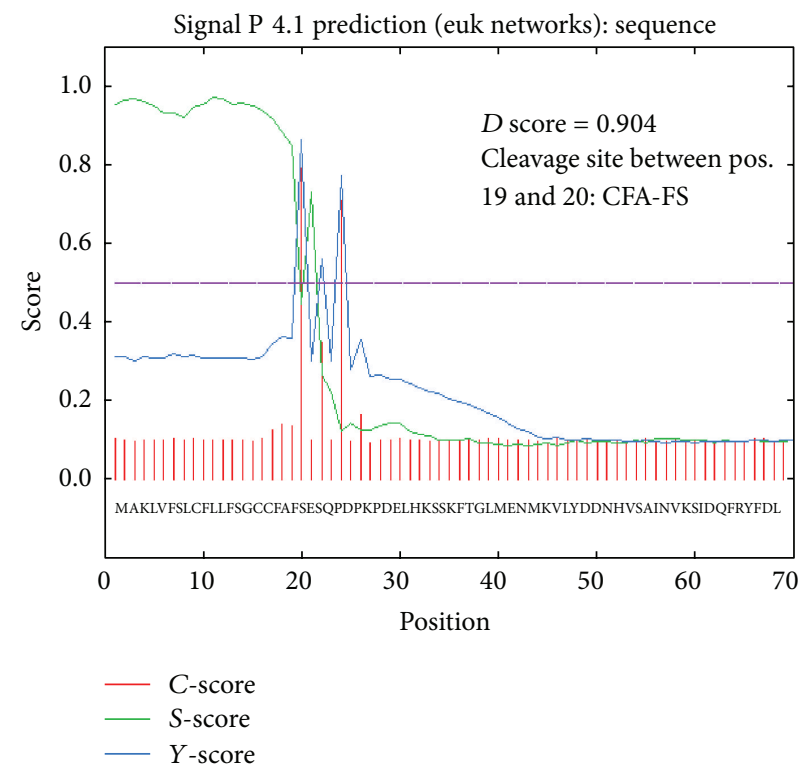

(f)

FIGURE 4: Characterization of soybean-derived mSEB. (a) and (b) Western blot analysis of soy-mSEB, E. coli-derived mSEB, and native SEB under nonreducing and reducing conditions. The ST108 soy-mSEB fragments detected under reducing conditions are labeled I and II, while those derived from 764 soy-mSEB are labeled III and IV. (c) and (d) N-terminal sequencing of soy-mSEB fragments detected under reducing conditions. Amino acids identified from N-terminal protein sequencing are shown in shaded boxes and aligned with the relevant portion of the $\mathrm{mSEB}$ protein sequence. The bacterial and soybean signal peptide sequences are underlined with bold typeface. Solid arrows indicate the predicted location for signal peptide cleavage and open arrows indicate observed N-termini. (e) and (f) SignalP 4.1 analysis of the ST108 and 764 soy-mSEB amino acid sequences. 
ST108

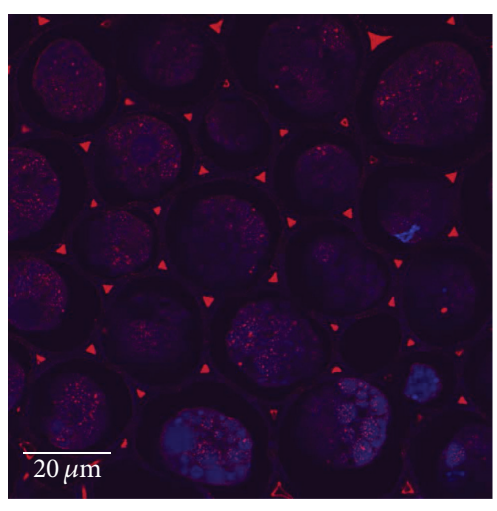

(a)

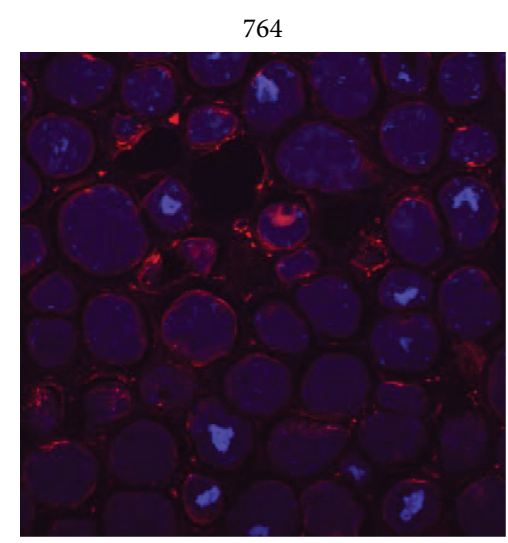

(b)

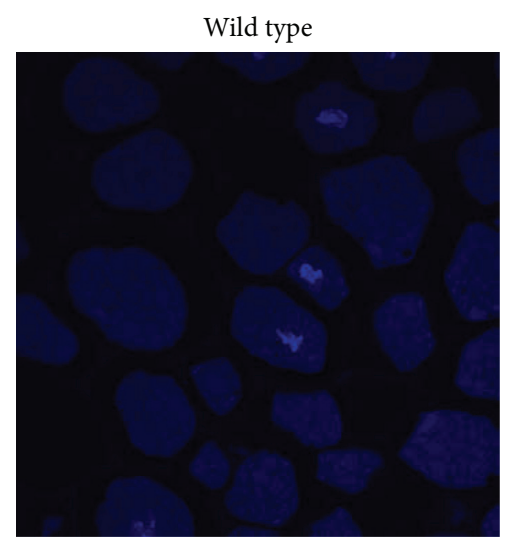

(c)

FIGURE 5: Immunohistochemical detection of soy-mSEB in T2 seeds. (a) ST108 seed section. (b) 764 seed section. (c) Nontransgenic (WT) seed section (control). Red fluorescence represents soy-mSEB protein that is either secreted into apoplastic spaces (ST108) or localized throughout the cell (764). DAPI staining of nuclear material is shown in blue. Samples were viewed at 20x magnification using confocal microscopy, and identical microscope parameters were used for photography of all samples shown.

disulfide loop region. The slight mobility difference observed with the E. coli-derived MSEB protein is the result of a Cterminal histidine tag included for purification.

Given the mobility of the two fragments detected under reducing conditions, we predicted that the smaller fragment represented an $\mathrm{N}$-terminal $\mathrm{mSEB}$ polypeptide while the larger fragment represented a $\mathrm{C}$-terminal $\mathrm{mSEB}$ polypeptide. To map the cleavage sites within soy-mSEB, the larger fragment from both ST108 and 764-derived proteins was subjected to $\mathrm{N}$-terminal protein sequencing. Results from the sequencing experiment identified the $\mathrm{N}$-terminal amino acid residues at the site of cleavage as SHQTDKRKTCMY. This sequence is present within the disulfide loop and confirmed that cleavage of mSEB occurred within this conserved loop region (Figures 4(c) and 4(d)).

Our final characterization of soy-mSEB involved the identification of the N-termini of both mature mSEB proteins. Note that the ST108-derived protein was engineered with a 27 -amino-acids bacterial signal peptide while the 764-derived protein was engineered with the 21-amino-acid soybean glycinin signal peptide. The ST108 and $764 \mathrm{mSEB}$ ORF sequences were analyzed using SignalP 4.1 software to predict the presence and location of potential signal peptides. This service predicted cleavage of ST108 between amino acids 27 and 28 and cleavage of 764 between amino acids 19 and 20 (Figures $4(\mathrm{e})$ and $4(\mathrm{f})$ ). To identify the mature $\mathrm{N}$-terminus of both soy-mSEB proteins, the smaller fragments obtained by treatment with $\beta$-mercaptoethanol were subjected to $\mathrm{N}$ terminal protein sequencing. In both cases, the $\mathrm{N}$-terminal sequence was identified as ESQPDPKPDEL. This sequence is identical to the $\mathrm{N}$-terminus of mature native SEB. These results verified that the heterologous bacterial signal peptide was accurately recognized and processed by the soybean signal peptidase machinery. This was also the case with the 764 events containing a heterologous glycinin leader peptide sequence.
3.3. Soy-mSEB Protein Cellular Localization. To determine soy-mSEB localization, immunohistochemistry was carried out on cotyledon tissue using an in-house anti-SEB antibody and an Alexa Fluor 594 goat anti-rabbit IgG secondary antibody. Confocal images show that mSEB derived from ST108 transformation events was secreted into apoplastic spaces (Figure 5(a)) while mSEB derived from 764 transformation events remained intracellular and appeared to be associated with the cell membrane (Figure 5(b)). DAPI staining of nuclear material showed that transgenic protein was also excluded from the nucleoplasm. Fluorescence was not observed in control (nontransgenic) tissues prepared using identical conditions (Figure 5(c)).

3.4. Seed Promoter Specificity. Practical use of soybean as a host for recombinant protein production would involve the harvest of seed and disposal of remaining biomass. To verify that soy-mSEB is present only in seed and not in the leftover biomass, protein was extracted from leaf, stem, and root material and compared with protein derived from master seed powder stocks. Western experiments confirmed that mSEB protein was only detectable in mature seed material and not in leaves, stems, and roots (Figure 6). Coomassie staining of the membranes used in these Western experiments confirmed the presence of plant protein on the blot.

\subsection{Soy-Derived SEB Is Immunologically Similar to Commer-} cial Forms of SEB. To evaluate immunogenicity of soy-mSEB relative to E. coli-derived $\mathrm{mSEB}$ and native SEB, an ELISA was performed using three separate anti-SEB antibodies. Soy-mSEB and E. coli-derived $\mathrm{mSEB}$ were purified as previously described [23] and purified native SEB was purchased commercially (Toxin Technology, Sarasota Florida). Equal amounts of the three purified proteins, along with cholera toxin (negative control), were coated onto ELISA plates and incubated with different anti-SEB antibodies. Absorbance 


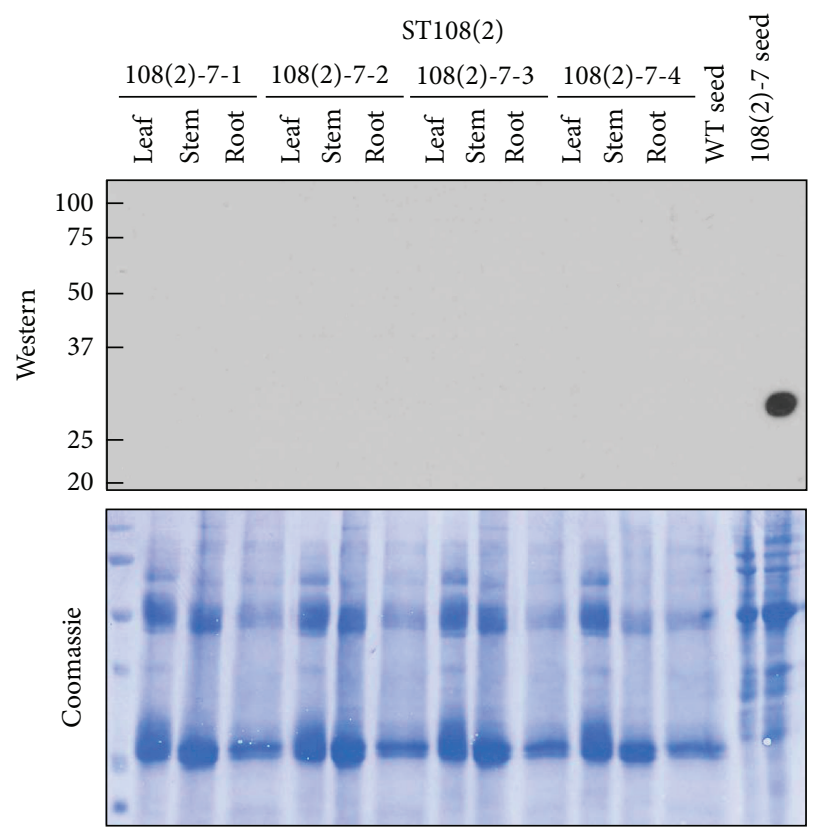

(a)

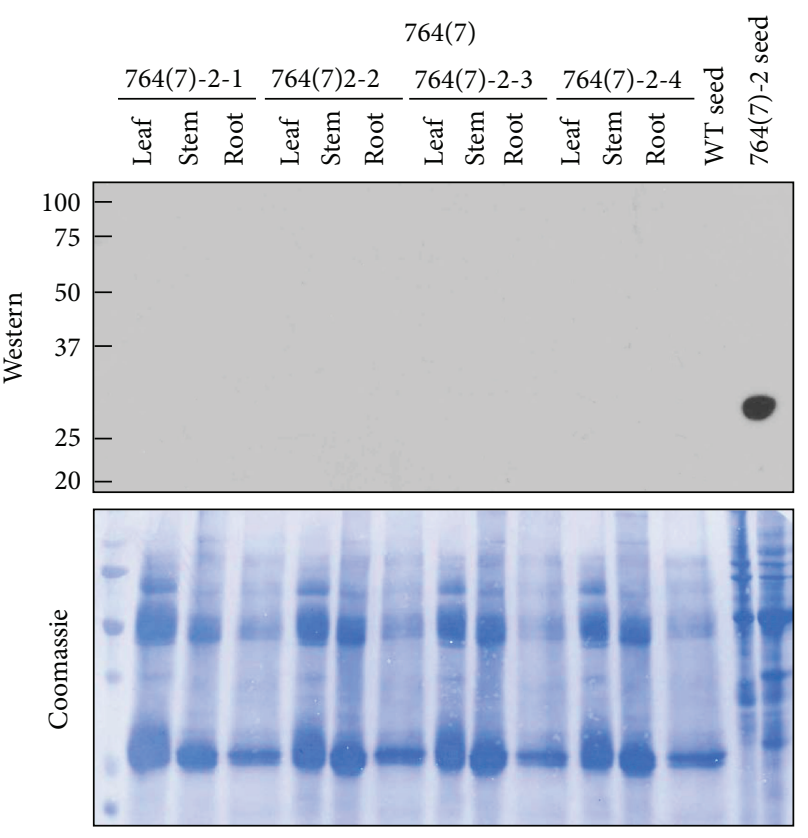

(b)

FIGURE 6: Western blot analysis of promoter specificity. Nonreducing SDS-PAGE conditions were used to separate $10 \mu \mathrm{g}$ total protein extracted from leaf, stem, and root tissues of the indicated T2 progeny. Equal amounts of T1 seed protein (parent) and nontransgenic (WT) seed protein were also included as controls. Top panels show X-ray film of the resulting Western blots while bottom panels show the blots used in this experiment following staining with Coomassie blue. Sizes of molecular mass standards are shown as kDa. (a) Data for events derived from ST108; (b) data for events derived from 764.

readings from these ELISAs are shown in Figure 7. An in-house rabbit anti-SEB polyclonal antibody recognized all three proteins similarly (Figure $7(a)$ ). Comparable results were observed in the absorbance readings from ELISAs using a commercially purchased sheep anti-SEB polyclonal antibody (Figure 7(b)). Since polyclonal antibodies are likely to bind both linear and conformational epitopes along the entire length of the SEB protein, these results suggested that soymSEB epitopes are intact. A third ELISA was performed using a commercial mouse monoclonal antibody which specifically detects one target epitope on the native SEB protein. Results from this ELISA (Figure 7(c)) were consistent with results from the previous two ELISAs in that absorbance readings for all three SEB proteins were similar. The results obtained here are consistent with the notion that nontoxic soy-mSEB protein is immunologically similar to both E. coli-derived mSEB and native SEB.

3.6. Immunization of Mice with Soy-mSEB Elicits an Antibody Response. To determine whether soy-mSEB could generate specific immunity, groups of mice were administered intraperitoneal injections of transgenic seed protein containing approximately $10 \mu \mathrm{g}$ of the soy-mSEB vaccine (along with cholera toxin adjuvant) on days 0,14 , and 28 . Blood was taken from each animal prior to immunization, and on day 42 , and the presence of serum antibodies against soy-mSEB was detected by ELISA (Figure 8). Mice immunized with soymSEB showed significant levels of IgG anti-SEB antibody production 14 days after immunization when compared to the prebleed. Antibody titers continued to increase by days 28 and 42 following booster vaccinations. These results demonstrate that the soy-mSEB vaccine candidate was effective in inducing antibodies which recognized native SEB.

\section{Discussion}

Over the past two decades, there has been substantial research on the expression of heterologous proteins in plants as a means to produce biopharmaceuticals. While numerous plant systems have been shown to support expression of heterologous proteins, the soybean has enormous potential with distinct advantages over these other systems. To date soybeans have been engineered to express a variety of therapeutic proteins [5, 26-28]. Soybeans have a high protein content ( $40 \%)$ making them an excellent host for increased expression and storage of recombinant protein. In the present study we report an expression level of $1.2 \%$ of TSP. If one assumes a vaccine dose of $10 \mu \mathrm{g}$, as is recommended for recombinant hepatitis B surface antigen immunizations [24], this translates into $\sim 76$ theoretical doses of human vaccine in a single seed. Although such calculations represent theoretical protein and do not take into account potential loses during purification they nonetheless represent significantly larger recoverable yield based on biomass when compared with other recombinant protein systems. Another important characteristic of soybeans is that these seeds have evolved as specialized compartments that store proteins for embryo nutrition. Therefore, soybeans possess metabolic adaptations 


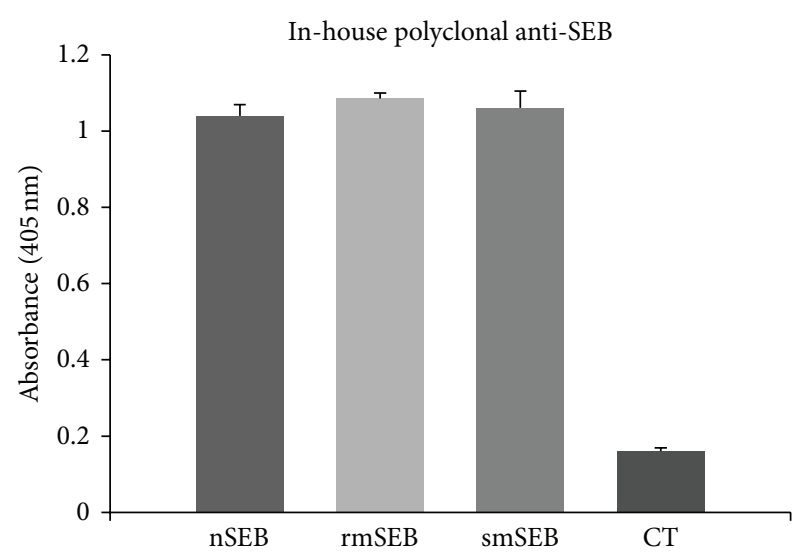

(a)

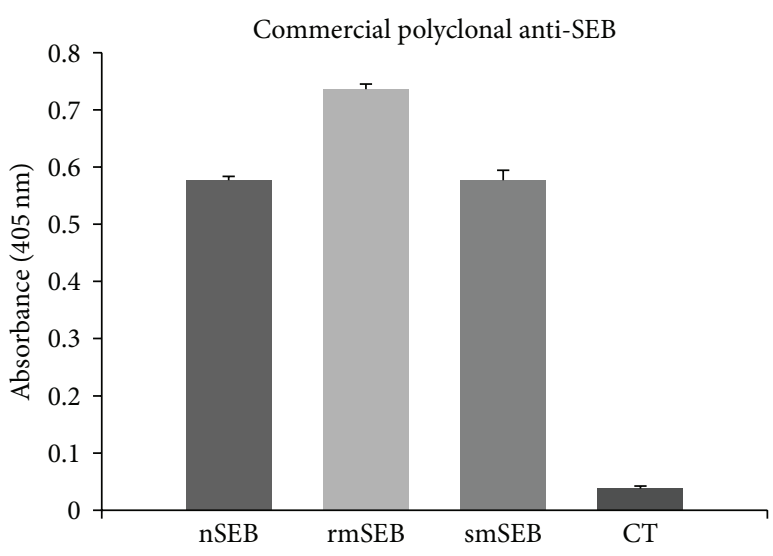

(b)

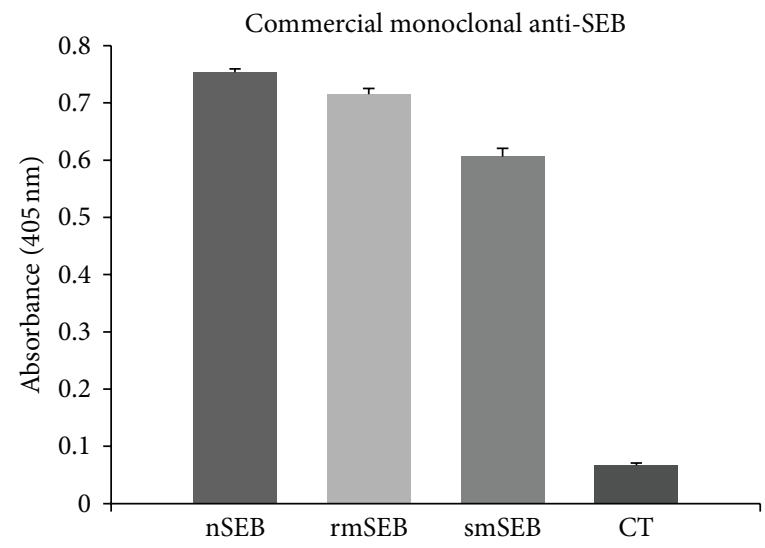

(c)

FIGURE 7: Immunogenicity of SEB proteins. ELISAs were used to determine relative immunogenicities of purified native SEB (nSEB), E. coliderived recombinant mutant SEB (rmSEB), and soy-derived mutant SEB (smSEB) proteins. Cholera toxin (CT) was included as a negative control. $100 \mathrm{ng}$ purified protein was coated in each well. All assays were performed in quadruplicate. (a) ELISA results using an in-house rabbit anti-mSEB polyclonal detection antibody. (b) ELISA results using a commercial sheep anti-SEB polyclonal detection antibody (Abcam number ab15925). (c) ELISA results using a commercial mouse anti-SEB monoclonal detection antibody (Abcam number ab6064). Values shown represent average absorbance values $(405 \mathrm{~nm})$. Error bars represent standard deviation.

that permit stable and long-term storage of proteins which in turn reduces the requirement for sophisticated and expensive storage conditions. Recombinant proteins expressed in soybean have proven to be stable for years at ambient temperatures $[25,29]$. This feature reduces or eliminates the need for a cold chain and allows for recombinant protein production to be a separate event with purification occurring at a later time if needed. Transgenic soybeans can also be used for production of therapeutic formulations that do not require purification. The efficacy of engineered therapeutics in crude soymilk formulations could lead to oral vaccines and other therapies that require little, if any, purification from other seed proteins. These simplified methods for expression, storage, and administration make soybean a cost-effective alternative to existing systems. Successful expression of the mSEB model vaccine antigen in this study demonstrates the practicality of soybean as a viable host for the expression of a vaccine candidate that is biochemically and immunologically functional.
A critical first step for efficient production of a vaccine protein in a recombinant system is to maximize the level of foreign protein expression in an effort to decrease production costs. Soybean seeds are the richest source of protein known, and while constitutive promoters can direct protein expression in seeds $[22,30]$, it is likely that higher accumulations of target proteins in seeds can be achieved using seedspecific promoters. In this study we used the soybean $7 \mathrm{~S} \beta$ conglycinin and $11 \mathrm{~S}$ glycinin seed storage promoters to target mSEB to seeds. These promoters have also been used by others to successfully express foreign proteins in seed $[5,26$, $28,29]$. The use of these promoters allowed us to target soymSEB expression to the seed and achieve high levels (1.2\% of TSP) of recombinant protein over multiple generations.

In this study we utilized different signal peptide sequences to evaluate subcellular targeting. SEB is a secreted protein which encodes a 27-amino-acid bacterial signal peptide sequence. If this signal peptide is also functional in plants, proteins could potentially be secreted to apoplastic spaces. 


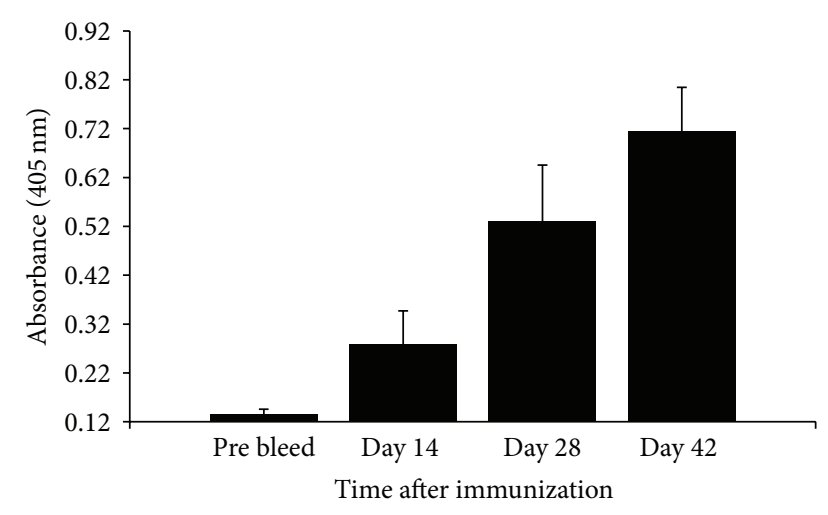

FIGURE 8: Anti-mSEB titers in mice following immunization. Groups of female BALB/c mice $(n=4)$ were immunized intraperitoneally on day 0 and boosted on days 14 and 28 days with $1 \mathrm{mg}$ transgenic seed extract plus adjuvant. Bleeds were collected just prior to immunization on days 0,14 , and 28 , and again on day 42. ELISAs were performed to determine serum IgG anti-mSEB reactivity. Absorbance values $(405 \mathrm{~nm})$ represent serum tested at a $1: 27000$ dilution and are presented as mean anti-mSEB titers and error bars represent standard deviation.

This location represents a different biochemical environment than intracellular spaces and therefore may impact foreign protein stability. We found that soy-mSEB containing the bacterial signal peptide was accurately processed by the soybean signal peptidase machinery, resulted in a protein with an N-terminus identical to the native protein, and was localized to apoplastic spaces. Since similar levels of soymSEB accumulated both extracellularly (with the bacterial signal peptide) and intracellularly (with the soybean glycinin signal peptide) it appears that $\mathrm{mSEB}$ does not have a preference for one subcellular location over the other. This is not surprising given that SEB is a highly stable toxin and has evolved its structure to remain stable under a variety of conditions. However, it is possible that apoplastic spaces are the preferred subcellular location for other recombinant proteins, and to this end we have shown that the bacterial SEB signal peptide may be useful in directing such proteins to those spaces. It is interesting to note that the signal peptide from another bacterial secreted protein (E. coli labile toxin subunit B, or LT-B) did not appear to have apoplasttargeting capabilities when tested in plants [31]. In that study, expression of chimeric LT-B genes containing either the native LT-B or maize y-zein signal peptide sequences resulted in the unexpected localization of LT-B to starch granules in maize endosperm [31]. In an effort to learn more about the targeting potential of the SEB signal peptide, we are currently testing whether other heterologous proteins can also be localized to apoplastic spaces when the SEB bacterial signal peptide is utilized [31].

Structural studies of SEB have shown the presence of a protruding disulfide loop in this toxin [32]. In the soybean seed environment it appears that this loop is susceptible to nicking by an unknown mechanism. We hypothesize that this nicking occurs either during or shortly after protein synthesis since extraction of seed protein in the presence of protease inhibitors did not prevent cleaved products from being detected (data not shown). Furthermore, incubation of E. coli-derived $\mathrm{mSEB}$ and native SEB protein preparations with soybean seed extracts did not induce nicking of those proteins, suggesting that seed proteases may not be involved. Previous reports in the literature describe nicking of native SEB $[9,33]$ and it has been suggested that this nicking is due to enzymatic or chemical hydrolysis during fermentation or purification. Interestingly, this previous work examined native SEB under reducing and nonreducing conditions and detected smaller fragments of SEB when the protein was exposed to reducing conditions; the site of nicking was mapped to the disulfide loop and occurred within 4 amino acids of the site identified [9]. This study also found that some commercial preparations of native SEB were comprised almost entirely of nicked protein while preparations from other vendors showed no evidence of internal cleavage [9]. Although the data presented in Figure 4 showed no signs of nicking in recombinant and native forms of SEB, when these same X-ray films were examined after extended exposure times there were bands present that indicated low levels of nicked SEB in both recombinant and native forms (data not shown). Thus, nicking within the SEB disulfide loop appears to be related to the SEB protein itself and not a phenomenon specific to any expression system. Importantly, the nicked forms of native SEB have been shown to retain full mitogenic activity as long as the disulfide bridge is intact [9]. A phenomenon involving what appears to be proteolytic cleavage of other plant-derived recombinant proteins has also been reported [28] and may be one reason why many recombinant proteins go undetected and associated experiments are deemed unsuccessful.

In order for a soy-based vaccine to be marketable it must be biologically equivalent to (or preferably superior to) an existing vaccine if one is already present in the marketplace. To date there is no commercial vaccine for SEB poisoning; therefore, the mSEB used as a "model" vaccine in this study could also function as an efficacious vaccine if it is shown to be immunogenic and confers protection following challenge with native toxin. To this end we examined the immunmoreactive profile of soy-mSEB and found it to be similar to that of E. coli-derived $\mathrm{mSEB}$ and native SEB (Figure 7). These observations suggested that immunogenic epitopes throughout soy-mSEB remain intact. The presence of significant levels of anti-SEB antibodies in blood sera of mice occurring within 14 days of immunization alludes to the efficacy of the soy-based mSEB vaccine.

\section{Conclusions}

In this study, a mutated nontoxic version of SEB (soy$\mathrm{mSEB}$ ) was produced in transgenic soybean seeds as a highly expressed vaccine. Soy-mSEB was specifically expressed within the soybean seed and was shown to be stably expressed over multiple generations. Soy-mSEB was successfully localized both intra- and extracellularly and accumulated equally in both subcellular locations. Soy-derived mSEB was shown to be biochemically and immunologically 
similar to recombinant and wild-type commercial forms of SEB. Additionally, functionality of the soy-mSEB as a vaccine antigen was demonstrated using mice which produced antiSEB titers in blood serum after vaccination with soy-mSEB. Taken together, these results show the efficacy of soy-derived $\mathrm{mSEB}$ and demonstrate the potential for soybean as a platform technology to produce pharmaceutical proteins.

To further explore the effectiveness of the soy-mSEB vaccine, current studies are underway to determine whether immunization with purified soy-mSEB confers protection in an animal model when challenged with the native toxin, and if so, whether such protection is comparable to or superior to protection obtained by vaccination with other recombinant forms of mSEB.

\section{Conflict of Interests}

The authors declare that there is no conflict of interests regarding the publication of this paper.

\section{Authors' Contribution}

Laura C. Hudson and Renu Garg contributed equally.

\section{Acknowledgments}

This investigation was supported by $\mathrm{NIH}$ awards R41AI072777 and R42AI072777 to Kenneth J. Piller (SoyMeds, Inc.).

\section{References}

[1] J. Boothe, C. Nykiforuk, Y. Shen et al., "Seed-based expression systems for plant molecular farming," Plant Biotechnology Journal, vol. 8, no. 5, pp. 588-606, 2010.

[2] M. Rai and H. Padh, "Expression systems for production of heterologous proteins," Current Science, vol. 80, no. 9, pp. 11211128, 2001.

[3] W. H. Brondyk, "Selecting an appropriate method for expressing a recombinant protein," Methods in Enzymology, vol. 463, pp. 131-147, 2009.

[4] E. E. Hood, D. R. Witcher, S. Maddock et al., "Commercial production of avidin from transgenic maizecharacterization of transformant, production, processing, extraction and purification," Molecular Breeding, vol. 3, no. 4, pp. 291-306, 1997.

[5] R. Powell, L. C. Hudson, K. C. Lambirth et al., "Recombinant expression of homodimeric $660 \mathrm{kDa}$ human thyroglobulin in soybean seeds: an alternative source of human thyroglobulin," Plant Cell Reports, vol. 30, no. 7, pp. 1327-1338, 2011.

[6] A. Herman, J. W. Kappler, P. Marrack, and A. M. Pullen, "Superantigens: mechanism of T-cell stimulation and role in immune responses," Annual Review of Immunology, vol. 9, pp. 745-772, 1991.

[7] T. S. Jardetzky, J. H. Brown, J. C. Gorga et al., “Threedimensional structure of a human class II histocompatibility molecule complexed with superantigen," Nature, vol. 368, no. 6473, pp. 711-718, 1994.

[8] A. C. Papageorgiou, H. S. Tranter, and K. R. Acharya, "Crystal structure of microbial superantigen staphylococcal enterotoxin
B at $1.5 \AA$ resolution: implications for superantigen recognition by MHC class II molecules and T-cell receptors," Journal of Molecular Biology, vol. 277, no. 1, pp. 61-79, 1998.

[9] D. Grossman, R. G. Cook, J. T. Sparrow, J. A. Mollick, and R. R. Rich, "Dissociation of the stimulatory activities of staphylococcal enterotoxins for T cells and monocytes," Journal of Experimental Medicine, vol. 172, no. 6, pp. 1831-1841, 1990.

[10] J. W. Kappler, A. Herman, J. Clements, and P. Marrack, "Mutations defining functional regions of the superantigen staphylococcal enterotoxin B," Journal of Experimental Medicine, vol. 175, no. 2, pp. 387-396, 1992.

[11] M. A. Woody, T. Krakauer, and B. G. Stiles, "Staphylococcal enterotoxin B mutants (N23K and F44S): biological effects and vaccine potential in a mouse model," Vaccine, vol. 15, no. 2, pp. 133-139, 1997.

[12] M. A. Woody, T. Krakauer, R. G. Ulrich, and B. G. Stiles, "Differential immune responses to staphylococcal enterotoxin $\mathrm{B}$ mutations in a hydrophobic loop dominating the interface with major histocompatibility complex class II receptors," The Journal of Infectious Diseases, vol. 177, no. 4, pp. 1013-1022, 1998.

[13] G. H. Lowell, R. W. Kaminski, S. Grate et al., "Intranasal and intramuscular proteosome-staphylococcal enterotoxin B (SEB) toxoid vaccines: immunogenicity and efficacy against lethal SEB intoxication in mice," Infection and Immunity, vol. 64, no. 5, pp. 1706-1713, 1996.

[14] B. G. Stiles, A. R. Garza, R. G. Ulrich, and J. W. Boles, "Mucosal vaccination with recombinantly attenuated staphylococcal enterotoxin B and protection in a murine model," Infection and Immunity, vol. 69, no. 4, pp. 2031-2036, 2001.

[15] R. G. Ulrich, M. A. Olson, and S. Bavari, "Development of engineered vaccines effective against structurally related bacterial superantigens," Vaccine, vol. 16, no. 19, pp. 1857-1864, 1998.

[16] J. W. Boles, M. L. M. Pitt, R. D. Le Claire et al., "Generation of protective immunity by inactivated recombinant staphylococcal enterotoxin $\mathrm{B}$ vaccine in nonhuman primates and identification of correlates of immunity," Clinical Immunology, vol. 108, no. 1, pp. 51-59, 2003.

[17] K. L. Hefferon and Y. Fan, "Expression of a vaccine protein in a plant cell line using a geminivirus-based replicon system," Vaccine, vol. 23, no. 3, pp. 404-410, 2004.

[18] T. N. Petersen, S. Brunak, G. Von Heijne, and H. Nielsen, "SignalP 4.0: discriminating signal peptides from transmembrane regions," Nature Methods, vol. 8, no. 10, pp. 785-786, 2011.

[19] P. Hajdukiewicz, Z. Svab, and P. Maliga, "The small, versatile pPZP family of Agrobacterium binary vectors for plant transformation," Plant Molecular Biology, vol. 25, no. 6, pp. 989-994, 1994.

[20] T. E. Clemente, B. J. LaVallee, A. R. Howe et al., "Progeny analysis of glyphosate selected transgenic soybeans derived from Agrobacterium-mediated transformation," Crop Science, vol. 40, no. 3, pp. 797-803, 2000.

[21] Z. Zhang, A. Xing, P. Staswick, and T. E. Clemente, "The use of glufosinate as a selective agent in Agrobacteriummediated transformation of soybean," Plant Cell, Tissue and Organ Culture, vol. 56, no. 1, pp. 37-46, 1999.

[22] K. J. Piller, T. E. Clemente, S. M. Jun et al., "Expression and immunogenicity of an Escherichia coli K99 fimbriae subunit antigen in soybean," Planta, vol. 222, no. 1, pp. 6-18, 2005.

[23] L. C. Hudson, B. S. Seaboltc, J. Odle, K. L. Bost, C. H. Stahlc, and K. J. . Piller, "Sub-lethal staphylococcal enterotoxin B challenge 
model in pigs to evaluate protection following immunization with a soybean-derived vaccine," Clinical Vaccine Immunology, vol. 20, no. 1, pp. 24-32, 2013.

[24] J. Goldfarb, S. V. Medendorp, H. Garcia, K. Nagamori, H. Rathfon, and D. Krause, "Comparison study of the immunogenicity and safety of 5- and 10- $\mu$ g dosages of a recombinant hepatitis B vaccine in healthy infants," Pediatric Infectious Disease Journal, vol. 15, no. 9, pp. 764-767, 1996.

[25] J. L. Oakes, K. L. Bost, and K. J. Piller, "Stability of a soybean seed-derived vaccine antigen following long-term storage, processing and transport in the absence of a cold chain," Journal of the Science of Food and Agriculture, vol. 89, no. 13, pp. 2191-2199, 2009.

[26] S.-H. Ding, L.-Y. Huang, Y.-D. Wang, H.-C. Sun, and Z.H. Xiang, "High-level expression of basic fibroblast growth factor in transgenic soybean seeds and characterization of its biological activity," Biotechnology Letters, vol. 28, no. 12, pp. 869$875,2006$.

[27] N. B. Cunha, A. M. Murad, G. L. Ramos et al., "Accumulation of functional recombinant human coagulation factor IX in transgenic soybean seeds," Transgenic Research, vol. 20, no. 4, pp. 841-855, 2011.

[28] D. A. Russell, L. A. Spatola, T. Dian et al., "Host limits to accurate human growth hormone production in multiple plant systems," Biotechnology and Bioengineering, vol. 89, no. 7, pp. 775-782, 2005.

[29] T. Moravec, M. A. Schmidt, E. M. Herman, and T. WoodfordThomas, "Production of Escherichia coli heat labile toxin (LT) B subunit in soybean seed and analysis of its immunogenicity as an oral vaccine," Vaccine, vol. 25, no. 9, pp. 1647-1657, 2007.

[30] L. Zeitlin, S. S. Olmsted, T. R. Moench et al., "A humanized monoclonal antibody produced in transgenic plants for immunoprotection of the vagina against genital herpes," Nature Biotechnology, vol. 16, no. 13, pp. 1361-1364, 1998.

[31] R. K. Chikwamba, M. P. Scott, L. B. Mejía, H. S. Mason, and K. Wang, "Localization of a bacterial protein in starch granules of transgenic maize kernels," Proceedings of the National Academy of Sciences of the United States of America, vol. 100, no. 19, pp. 11127-11132, 2003.

[32] M. A. Olson and L. Cuff, "Molecular docking of superantigens with class II major histocompatibility complex proteins," Journal of Molecular Recognition, vol. 10, pp. 277-289, 1997.

[33] L. Spero, J. R. Warren, and J. F. Metzger, "Effect of single peptide bond scission by trypsin on the structure and activity of Staphylococcal enterotoxin B," Journal of Biological Chemistry, vol. 248 , no. 21 , pp. $7289-7294,1973$. 

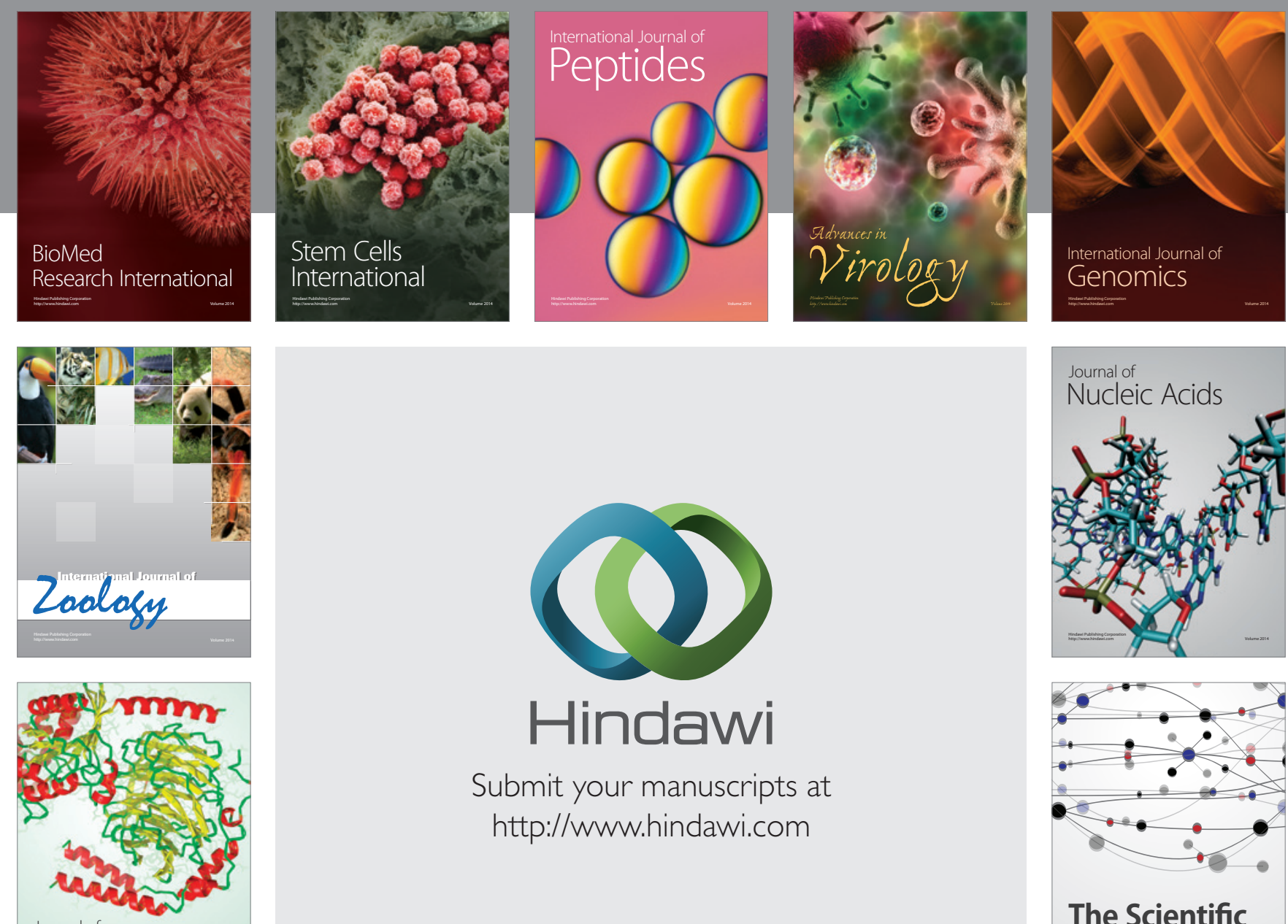

Submit your manuscripts at

http://www.hindawi.com

Journal of
Signal Transduction
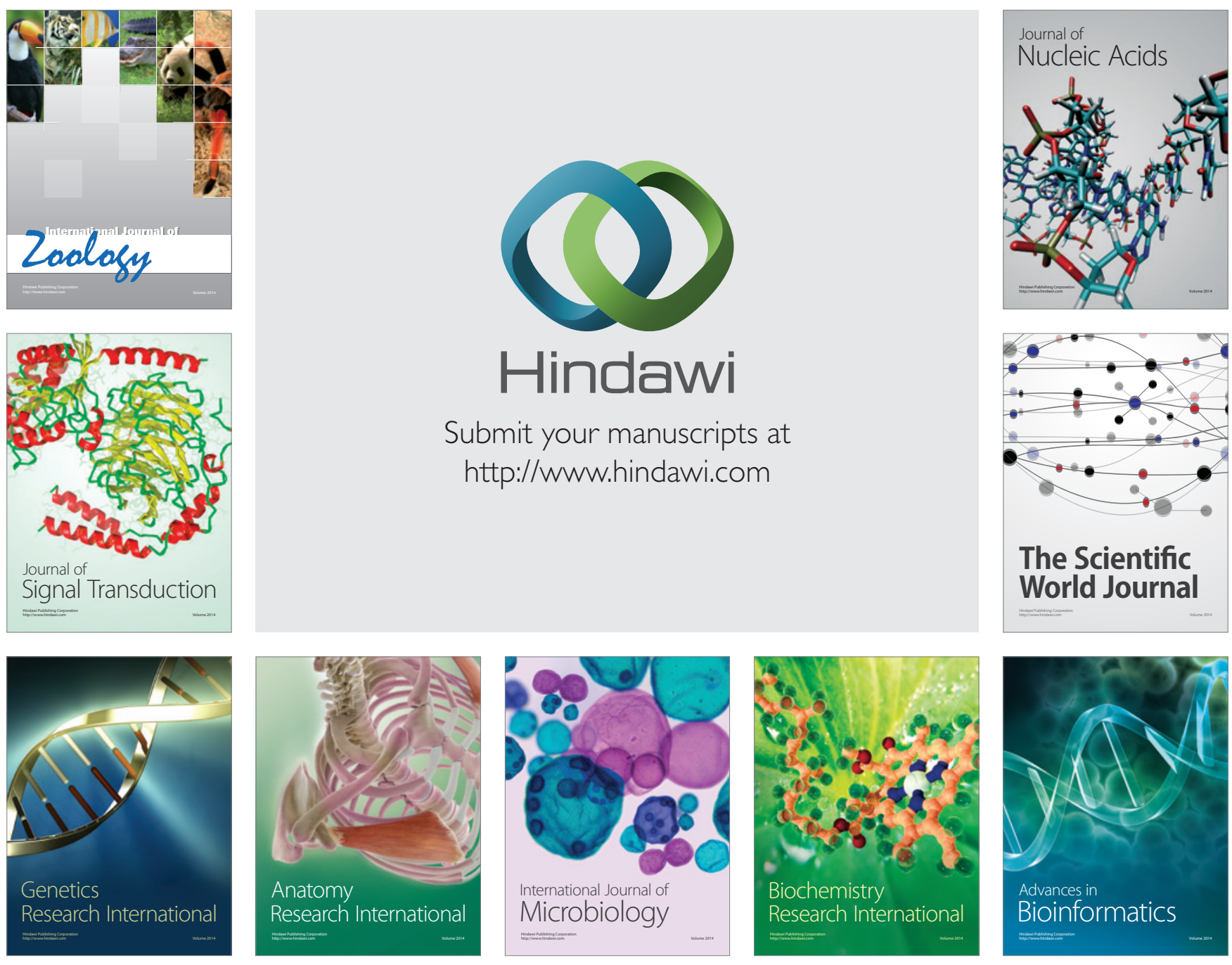

The Scientific World Journal
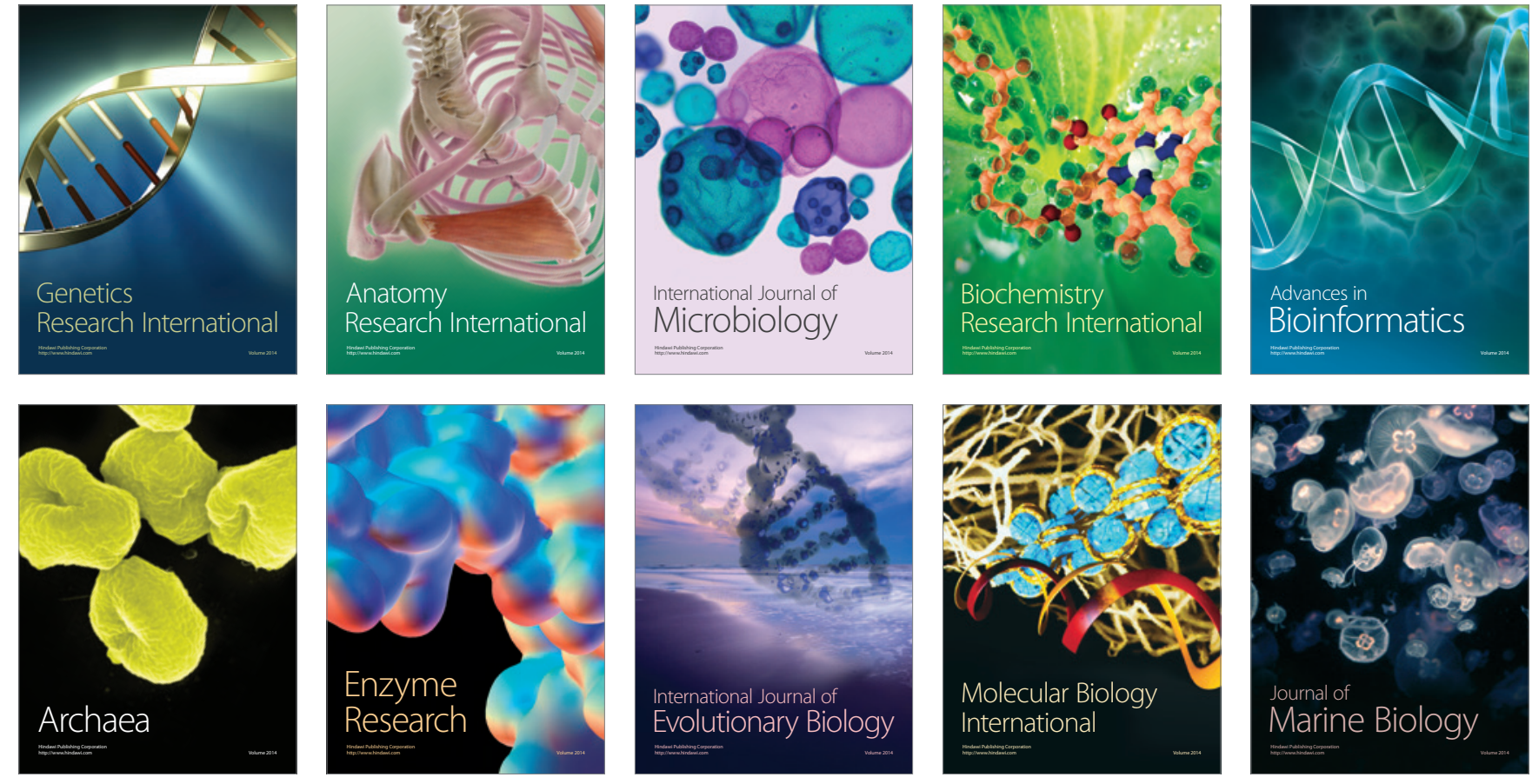